\title{
Medical Neglect of the Child
}

\author{
COSMIN ALEXANDRU CIORA ${ }^{1}$, VLAD DUMITRU BALEANU $1,2 *$, DRAGOS VIRGIL DAVITOIU², DANIEL IULIAN VOICULESCU ${ }^{3 *}$, \\ CRISTIAN VIRGIL LUNGULESCU4, TIBERIU STEFANITA TENEA COJ AN ${ }^{5}$, BOGDAN SOCEA ${ }^{6}$, DRAGOS OVIDIU ALEXANDRU ${ }^{7 \#, ~}$ \\ RADU STANESCU ${ }^{8}$, MIHAI RELU STANESCU ${ }^{8}$, GIGI CALIN ${ }^{9}$, RAMONA MIHAELA NEDELCUTA ${ }^{9}$ \\ ${ }^{1}$ Carol Davila University of Medicine and Pharmacy, Discipline of Gastroenterology and Hepatology, 8 Eroii Revolutiei Blvd., \\ 050474, Bucharest, Romania \\ 2University of Medicine and Pharmacy of Craiova, Surgery Department, Clinical Emergency Hospital Sf. Pantelimon Bucharest, \\ 340-342 Pantelimon Road, 021659, Bucharest, Romania \\ ${ }^{3}$ University of Medicine and Pharmacy Carol Davila Bucharest, Department of Surgery Universitary Emergency Hospital Bucharest, \\ 169 Splaiul Indepenei, 050098, Bucharest, Romania \\ ${ }^{4}$ University of Medicine and Pharmacy of Craiova, Department of Oncology, 2 Petru Rares Str., 200349, Craiova, Romania \\ EUniversity of Medicine and Pharmacy of Craiova, Department of Surgery, CFR Hospital of Craiova, Stirbei-Voda Str., 200374,Craiova, \\ Romania \\ ${ }^{6}$ General Surgery Clinic, Emergency Clinical Hospital Sfantul Pantelimon, 340-342 Pantelimon Road, 021659, Bucharest, Romania \\ ZUniversity of Medicine and Pharmacy of Craiova, Department of Medical Informatics and Biostatistics, 661 Mai Blvd, 200638, \\ Craiova Romania \\ ${ }^{8}$ University of Medicine and Pharmacy of Craiova, Department of Morphological Sciences, Petru Rares Str., 200349, Craiova, \\ Romania \\ IUniversity of Medicine and Pharmacy of Craiova, Pediatrics Department, 2 Petru Rares Str., 200349, Craiova, Romania
}

The medical carelessness of the child still remains an actual topic despite the evident evolution of the society from the last years. The study has been made during 12 months on 370 of hospitalized cases, showing worrying levels of the medical carelessness percent which attains to $80 \%$. The percent is linked to modifications of certain parameters, the elaboration and the use of standardized questionnaires may represent an useful instrument of the medical abuse recognition since the anamnesis moment.

Keywords: neglect, child, abuse

The consequences of child neglect are not benign when compared with other forms of abuse. More than $30 \%$ of child maltreatment deaths were attributed to neglect in isolation, with $22.9 \%$ attributed to physical abuse and $40.8 \%$ attributed to multiple forms of maltreatment [1]. Neglect is often a neglected form of child maltreatment despite the significantnumbers of children affected by the problem and its potential for serious consequences. Child physical abuse and sexual abuse continue to receive the greatest amount of professional attention and research.

\section{Experimental part}

Methods and Materials

Defining neglect is not an easy task. The World Health Organization [2] defines child neglect as the failure to provide for the development of the child in all spheres: health, education, emotional development, nutrition, shelter, and safe living conditions. This failure must be gauged in the context of resources reasonably available to the family or caretakers and whether it causes or has a high probability of causing harm to the child's health or physical, mental, spiritual, moral, or social development. The WHO definition also includes the failure to provide proper supervision and protect children from harm whenever possible [2]. Appleton [3] emphasizes that neglect can rarely be identified from a specific incident; rather, itmost often relies on health care providers, teachers, day care workers, and other professionals working with children to make a decision about the inadequacy of ongoing care of the child within the context of the child's family.
In 2015, 4.4 million reports of alleged child maltreatment were made to Child Protective Services (CPS) in the US involving 7.2 million children. About 2.1 million of these reports were investigated in detail and about 683,000 maltreated children were identified. Both sexes are affected equally; the younger the child, the higher the rate of victimization.

About three fifths of all reports to Child Protective Services were made by professionals who are mandated to report maltreatment (eg, educators, law enforcement personnel, social services personnel, legal professionals, day care providers, medical or mental health personnel, foster care providers).

Of substantiated cases in the US in 2015, 75.3\% involved neglect (including medical neglect), 17.2\% involved physical abuse, $8.4 \%$ involved sexual abuse, and 6.9\% involved other forms of abuse including psychological maltreatment. Many children were victims of multiple types of maltreatment.

About 1670 children died in the US from maltreatment in 2015, about three quarters of whom were $<3 \mathrm{yr}$. Over $70 \%$ of these children were victims of neglect and $44 \%$ were victims of physical abuse with or without other forms of maltreatment. More than three quarters of perpetrators were parents acting alone or with other individuals, and about $25 \%$ of child abuse fatalities were perpetrated by the mother acting alone [4].

Certain familial/caregiver factors place children at increased risk of experiencing neglect. These factors are essential barriers that diminish the parent's ability to provide adequate care. When considering a diagnosis of

* email: baleanuvlad@gmail.com; Phone: 0040765865886 
neglect, it is crucial to assess the situation for potential barriers preventing the parent/caregiver from providing adequate care [5]. A major factor limiting the ability to provide adequate care is a lack of financial resources, which can affect nearly every aspect of care from health care to education. Poverty can affect the ability of the parents to provide adequate supervision (e.g., when the parents need to work but do nothave the resources to pay for child care), housing (which can also affect the child's educational status, because a stable address is necessary for school enrollment), dental care, nutrition, clothing, and safety (car seats are expensive, and parents may not have the resources to purchase one). Clearly, familial financial resources and the lack thereof can have serious negative consequences on the ability of the parents to meet even the most basic physical needs of their child. Specific familial economic factors may be associated with an increased likelihood of child neglect. Slack and colleagues [6] found poverty to be a strong predictor of child neglect. Specifically, receiving financial assistance from a family member and receiving food from a food pantry were associated with increased neglect, which could indicate that families who resort to these forms of assistance may be experiencing severe economic stress and struggling to get by. Some parents/caregivers may have physical health, cognitive, mental health, or substance abuse concerns that limit their ability to provide safe and adequate care for their children [6]. Physical health problems can obviously impair caregiver ability to provide basic physical care (e.g., bathing, preparing food, and laundering clothes). Caregiver cognitive, mental health or substance abuse concerns may affect the caregiver's ability to understand the importance of providing nearly every aspect of adequate care, from health care to love and nurturance. Parents with these concerns may honestly not know how to meet even the most basic needs of their children or may be so impaired that they are oblivious to the needs of their children.

Cultural and/or religious beliefs may limit the ability of the parent/caregiver to meet their children's needs at a level that is deemed adequate by the larger society.

J ehovah's Witnesses or Christian Scientists may have religious beliefs that conflict with the recognized standard of medical care for a particular diagnosis. Certain cultures also engage in folk practices to treatillness (e.g.,coining or cupping) that may affect a parent's decision to seek medical care for his or her children when they are ill, and some cultures have practices to mark rites of passage (e.g., genital mutilation) that are viewed as neglectful or abusive to the larger society.

Neglect can be represented in many different forms. Box 1 provides a list of different types of neglect, with some specific examples of neglectful situations. Medical and supervisory neglect will be discussed in some detail, because the PNP may be more likely to address these types of neglect in practice. Neglect is multifaceted, and neglect and other forms of child maltreatment rarely occur in isolation. A neglected child is at increased risk to also experience physical, sexual, or emotional abuse. A child also may experience multiple types of neglect.

- Physical (e.g., failure to provide necessary food or shelter, or lack of appropriate supervision)

- Medical (e.g., failure to provide necessary medical or mental health treatment)

- Educational (e.g., failure to educate a child or attend to special education needs)

- Emotional (e.g., inattention to a child's emotional needs, failure to provide psychological care, or permitting the child to use alcohol or other drugs).
The effects of neglect on children can be significant and long term, with children's physical and mental health and psychosocial and cognitive development affected [7]. The physical effects of neglect can be relatively immediate, such as injuries resulting from inadequate supervision, delay/failure to seek proper medical care, or failure to follow through with the recommended health care plan. Physical consequences of neglect can range from minor to the most severe, and can even result in death.

Studies have linked neglect to negative health care consequences extending into adulthood. Teicher and colleagues [8] found differences in the brains of children who experienced neglect. Smaller sizes of the corpus callosum were noted. The Adverse Childhood Experiences Study investigators found that children who experienced neglect were more likely to experience liver disease as adults [9], ischemic health disease [10](Dong et al., 2004), and asthma and lung cancer [11]. Tietjen and colleagues [12] suggested a relationship between neglect and migraines and comorbid pain conditions in adults. Specific elements of neglect were linked to adult delinquency: failure to supervise; a disorganized, chaotic family; and parental separation [13]. Hayden, Hussey, and Halpern [14] found that experiencing physical neglect as a child placed young adult women at increased risk of engaging in highrisk sexual behaviors and testing positive for sexually transmitted infections (e.g., chlamydia, gonorrhea, and trichomonas).

Neglected children have more problems with consistent school attendance, repeating grades, and poorer grades than do non-neglected peers. Children removed from their homes for neglect experienced more days in out-of-home care and were less likely to reunify than were children removed for abuse $[15,16]$.

Davidson-Arad and colleagues [17, 18], in a study to compare characteristics of children assessed as neglected versus those assessed as accident victims, found that neglected children were twice as likely as accident victims to have had health problems and three times more likely to have had developmental problems. Neglected children were more likely to have had prior psychological treatment and a previous hospital referral to a community agency. Families of neglected children are more likely to live in poverty and be clients of the social services and receive state support, and their mothers are more likely to be unemployed [16].

\section{Results and discussions}

The 2 years old OD patientfrom rural area presents with anorexia, intermittent vomiting, diarrhea. The child comes from rural areas from a family with food taboos (ovo-lactovegetarians).

The condition to the hospital admission is impaired pale, uncooperative, labeled with psychomotor retardation, precordial systolic grade 2 murmur, pale skin, sabural tongue, supple abdomen, lazy abdominal skin fold, vomiting, diarrhea, weight $=10 \mathrm{~kg}$.

From antecedents, anorexia is installed for about 6 months, it is refractory to treatment, and after collaboration with the general practioner it is contemporary with equilibrium disturbances, with the stress of the psychomotor retardation and the consequence of a convulsive crisis with spontaneous remission.

Immediately after admission, urgent measures are instituted with hydroelectrolytic recovery, broad spectrum antibiotic treatment, antidiarrheal treatment, but despite all the measures applied, the patient died within the first 4 hours from admission. 
The cause of death is determined by the anatomopathological exam - cerebral abscess on $1 \frac{1}{2}$ left hemisphere, which explains the equilibrium disorders, convulsions, anorexia, vomiting, infectious impregnation, anemia, the serious condition of the child.

The family's ignorance, the low education grade, poor hygiene, limited access to information and medical care make abuses on children possible which end dramatically.

This was the starting point for a study on child health abuse.

The abuse refers to any form of intentional violence against the child or any harmful treatment that does not always involve violence. In the case of child abuse, there is an unequal relationship in relationships where the abuser holds control or can influence / manipulate the child's actions and deliberately and consciously endangers the development, health or life of the child on a long term.

Among the many forms of abuse (verbal, physical, alienation, emotional, etc.), is distinguished a particular form - the abuse by medical aid deprivation. This is a form of bad treatment applied to the minor, a neglect of parental inertia in giving access / medical treatment to the child, resulting in damage the child's health.

Medical negligence may be permanent, as in the case under study, resulting in serious death or temporary situations, related to the parents' inability to notice changes in the child's state of health and to act properly by presenting to the physician.

A 1-year study was conducted on 370 hospitalized patients with various health conditions and ages between $0-3$ years. From these, $303(82 \%)$ have presented a form of medical neglect. The majority were from rural areas (79\%), 239 cases and 64 from urban areas (figs. 1,2).

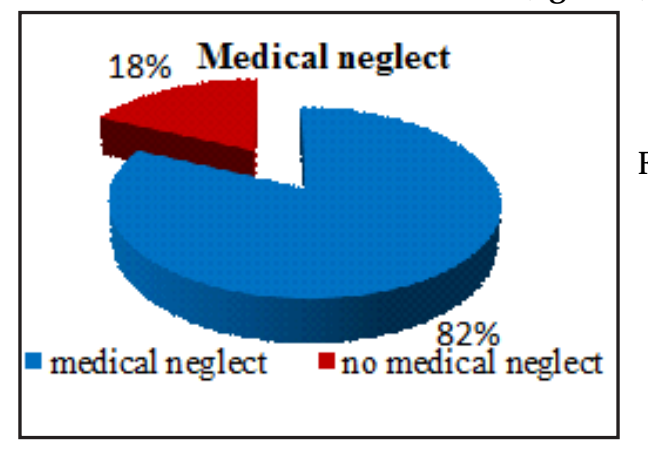

Fig. 1. Medical neglect

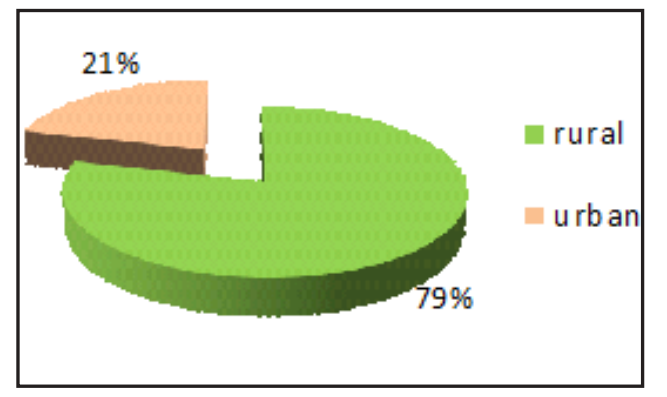

Fig. 2.

Children origin

A questionnaire was developed with certain characteristics: parents age, the degree of instruction, the economic and financial situation, mono-/biparental families, abandoned children, natural alimentation, the access to the medical services, food/religious taboos, absence or excess hygiene, affiliation to sects/ethnicities, drug abuse, other forms of physical / emotional abuse.

The results have been somewhat surprising. Extreme variants ( $>40$ and $<15$ ) were found to be $15 \%$ from the total number of cases, $70 \% / 30$ cases being minor mothers from rural areas.
Most mothers showed a low or medium level of schooling - 50 had higher education, 147 graduated high school and 65 primary (fig. 3).

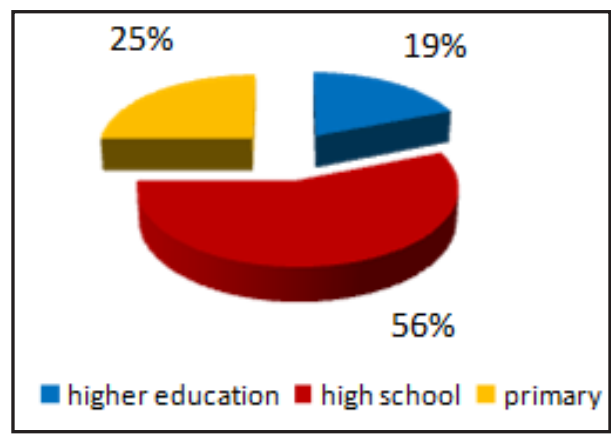

Fig. 3. Mother education

The traditional family was found in $77 \%$ of the cases, in the rest of the cases the children came from monoparental families or they were brought up by grandparents / relatives $-6 \%$ of the cases.

The natural food was a common factor, positive in 35\% from urban children $/ 22$ cases and $62 \%$ from rural areas 148 cases, until 6 months.

It took into account the emotional impact, not the health benefits.

Food taboos have met exclusively in the urban area, until $8 \%$ of children/avoiding animal proteins, replacing regular milk with soy/almond milk, eliminating foods with high histamine content.

The access to medical services, paradoxically, from parents' statements was not an impediment to $23 \%$ of all cases, all from rural areas (fig. 4).

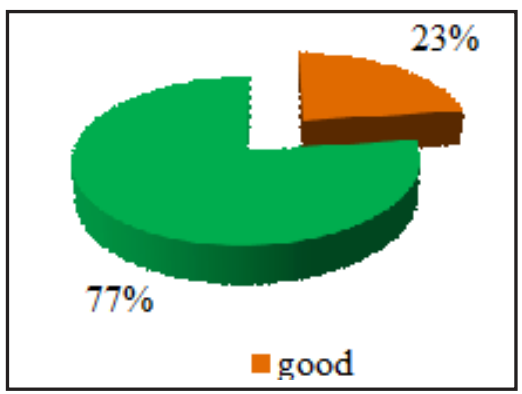

Fig. 4. Medical services access

Regarding other forms of abuse (physical, emotional, etc.), the proportion was relatively equal to urban (34\%) and rural (37\%) (fig. 5).

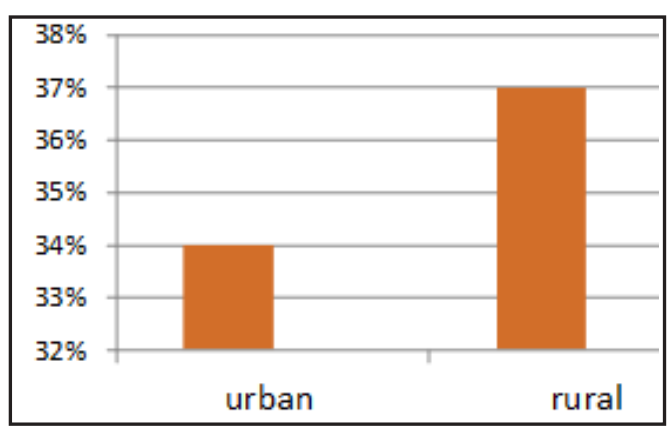

Fig. 5. Forms of abuse

Here comes the syndrome of bruised child, sentimental blackmail, physical punishment, or emotional restriction.

The affiliation to ethnicity/religious sects belonged to $9 \%$ of all cases.

Hygiene deficiency occurred in $42 \%$ of rural areas and $19 \%$ in urban areas.

Drug abuse, in particular antibiotics administrated unexpected, has been found out at $15 \%$ of cases ( 45 children) and from these ones $73 \%$ in rural areas ( 33 cases) and $27 \%$ from urban areas ( 12 cases) (fig. 6). 


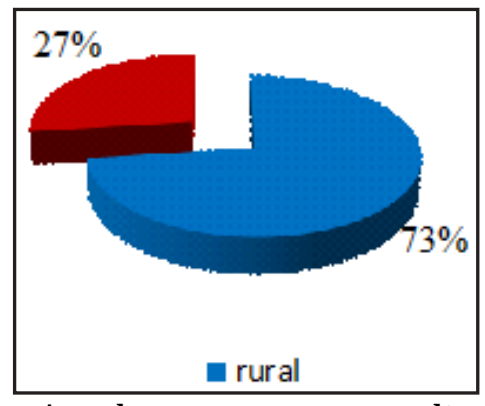

Fig 6. Drug abuse

Another parameter studied was the number of hospitalization days for the studied group.

In previously abused/deprived children, it was prolonged on average by $1-2$ versus patients who did not experience a form of abuse. The family's socio-economic level is inversely proportional to the possibility of neglect.

\section{Conclusions}

Elaboration of patented questionnaires could be a useful tool for the clinician to appoint since the beginning the child as being medically neglected. Among the multiple classified forms of abuse, child neglect can take serious forms: from severe deficiencies, treatment deficiency to exitus. Increasing the level of education, the socioeconomical level is correlated conversely proportional with medical abuse. The abuse is represented more or less, excess medication being as dangerous as lack of medication. The intervention of primary medicine in disadvantaged areas could improve the level of information deficits and neglect of the child. The integration into the curriculum of medical education courses could reduce the perception errors on the child's health condition.

\section{References}

1.***CHILD WELFARE INFORMATION GATEWAY. (2012). Child Maltreatment 2010: Summary of key findings. Washington, DC: U.S. Department of Health and Human Services, Childrens Bureau.

2.***WORLD HEALTH ORGANIZATION. (1999). Report of the consultation on child abuse prevention, 29-31 March 1999, WHO. Geneva. Geneva, Switzerland: World Health Organization.

3. APPLETON, J. V. (2012). Perspectives of neglect. Child Abuse Review, $21,77-80$

4.***US DEPARTMENT OF HEALTH \& HUMAN SERVICES ADMINISTRATION FOR CHILDREN AND FAMILIES ADMINISTRATION ON CHILDREN, YOUTH AND FAMILIES: Child maltreatment 2015. Available at the Children's Bureau web site.

5. JENNY, C. (2007). Recognizing and responding to medical neglect. Pediatrics, 120, p.1385-1389.
6. SLACK, K., BERGER, L., DUMONT, K., YANG, M., KIN, B., EHRHARDDIETZEL, S., \& HOLL, J. (2011). Risk and protective factors for child neglect during early childhood: A cross-study comparison. Children and Youth Services Review, 33, p.1354-1363.

7.DUBOWITZ, H. (2009). Tackling child neglect: A role for pediatricians. Pediatric Clinics of North America, 56, p.363-378.

8. TEICHER, M. H., DUMONT, N. L., ITO, Y., VAITUZIS, C., GIEDD, J. N., \&ANDERSEN, S. L. (2004). Childhood neglect is associated with reduced corpus callosum area. Biological Psychology, 56, p.80-85.

9. DONG, M., DUBE, S. R., FELITTI, V. J., GILES, H. P., \& ANDA, R. F. (2003). Adverse childhood experiences and self-reported liver disease: New insights into a causal pathway. Archives of Internal Medicine, 163, p.1949-1956.

10.DONG, M., GILES, W. H., FELITTI, V. J., DUBE, S. R., WILLIAMS, J. E., CHAPMAN, D. P., \& ANDA, R. F. (2004). Insights into causal pathways for ischemic heart disease: Adverse childhood experiences study. Circulation, 110, p.1761-1766.

11. BROWN, D. W., YOUNG, K. E., ANDA, R. F., FELITTI, V. J., \& GILES, H. P. (2006). Asthma and the risk of lung cancer. Findings from the adverse childhood experiences. Cancer Causes Control, 17, p.349350.

12.TIETJ EN, G. E., BRANDES, J. L., PETERLIN, B. L., ELOFF, A., DAFER, R. M., STEIN, M. R., . KHUDER, S. A. (2009). Childhood maltreatment and migraine (part 1). Prevalence and adult revictimization: A multicenter headache clinic study. Headache, 10, p. 20-30.

13. MAUGHAM, D., \& MOORE, S. C. (2010). Dimensions of child neglect: An exploration of parental neglect and its relationship with delinquency. Child Welfare, 89, p. 47-65.

14. HAYDEN, A. A., HUSSEY, J. M., \& HALPERN, C. T. (2011). Childhood abuse and neglect and the risk of STDs in early adulthood. Perspectives on Sexual and Reproductive Health, 43, p. 16-22.

15. BUNDY-FAZIOLI, K., WINOKUR, M., \& DELONG-HAMILTON, T. (2009). Placement outcomes for children removed for neglect. Child Welfare, 88, p.85-102.

16. VLADU, I.M., RADU, L., GIRGAVU, S.R., TENEA COJ AN, T.S., ENE, C.G., CALBOREAN, V., GHEORMAN, V., CLENCIU, D. Alteration of Glucidic Metabolism in Relation with Visceral Adiposity Index. Rev. Chim. (Bucharest), 69, no. 9, 2018, p. 2479-2481.

17. CORICI O.M., TANASIE C.A., ALEXANDRU D.O., FLORESCU M.C., COMANESCU M.V., KAMAL K.C., TENEA-COJAN T.S., IANCAU M, DINESCU S.N. A morpho-functional study using PEP/LVET ratio and global longitudinal strain in patients with dilated cardiomyopathy. ROM J MORPHOL EMBRYOL. 2018, 59(1), p.93-103

18. DAVIDSON-ARAD, B., BENBENISHTY, R., CHEN, W., GLASSER, S., ZUR, S., \& LERNER-GEVA, L. (2010). Distinguishing neglect from abuse and accident: Analysis of the case files of a hospital child protection team in Israel. Health and Social Care in the Community, 18, p. 614 623.

$\overline{\text { Manuscript received:4.02.2019 }}$ 